\title{
Perspectives in Surgical Infections: What Does the Future Hold?
}

\author{
Lena M. Napolitano
}

I AM HONORED AND HUMBLED to stand before you today, as I follow in the footsteps of the distinguished prior Surgical Infection Society (SIS) Presidents, Doctors Stephen F. Lowry, John C. Marshall, Timothy R. Billiar, Edwin A. Deitch, and Philip S. Barie, who have served in the last five years. As I contemplated the choice of topic for my Presidential Address, I reviewed the addresses of each of these individuals (Fig. 1). I also reviewed the history of the SIS and its first President, Doctor William A. Altemeier, a true pioneer in surgical infectious diseases.

The topic of Doctor Altemeier's presidential address was "Sepsis in Surgery," and the paper was read at the first annual meeting of the Society in Chicago on April 25, 1981. In this address, he stated: "Infection has always been a prominent feature of human life, and sepsis in modern surgery continues to be a significant health problem throughout the world. For this reason, the Surgical Infection Society has been formed and is holding its first meeting here today" [1]. I hope you will indulge me today, as I have chosen to return to the topic of surgical infections to provide a current perspective and to contemplate what the future holds and the role the SIS may play.

I review three categories of surgical infections: (1) surgical site and skin infections; (2) complicated intra-abdominal infections, and (3) nosocomial and other healthcare-associated infections, including ventilator-associated pneumonia (VAP) and catheter-related blood stream infections (CR-BSI). Lastly, I touch on the topic of acute care surgery and discuss the role the SIS may play in the development of this emerging field.

\section{Surgical Site and Skin Infections}

As we are all aware, surgical site infections (SSIs) are the most common nosocomial infections among surgical patients and the third most common nosocomial infection overall. Such infections occur after approximately $3 \%$ of all operations and result in greater lengths of stay (LOS) and additional costs [2,3]. In 2002, in the U.S., an estimated 14 million operative procedures were performed. Among the four healthcare-associated infections (pneumonia, SSI, urinary tract infection, and blood stream infection), SSIs were the second most common, accounting for $17 \%$ of all healthcare-associated infections among hospitalized patients. A similar rate was obtained from National Healthcare Safety Network (NHSN) hospitals reporting data in 2006-2008 (15,862 SSIs following 830,748 operative procedures, with an overall rate of nearly $2 \%$ [4]. The risk of SSI is strongly associated with wound class, being low for the clean and clean-contaminated incisions and high for the contaminated and dirty-infected incisions.

Three independent variables are associated with SSI risk in a system developed by the National Nosocomial Infections Surveillance System (NNIS) [5,6]. The NHSN was established in 2005 to integrate and supersede three legacy surveillance systems at the U.S. Centers for Disease Control and Prevention (CDC): NNIS, the Dialysis Surveillance network (DSN), and the National Surveillance System for Healthcare Workers (NaSH). Similar to the NNIS, NHSN facilities report their healthcare-associated infection surveillance data voluntarily for aggregation into a single national database.

The NHSN SSI Risk Index includes an American Society of Anesthesiologists (ASA) score $>2$, classification of a surgical site as contaminated or dirty, and prolonged operation [7-9]. Although the risk of infection increases within an incision class, it also is dependent within each class on the NNIS classification. The basic SSI Risk Index used in NHSN assigns surgical patients to categories on the basis of the presence or absence of three major factors (Table 1). The patient's SSI risk category is simply the number of these factors present at the time of the operation. The laparoscopic surgical approach is associated with a lower SSI incidence, and a modified risk index (category minus 1 point when certain procedures are performed with a laparoscope) has been created to address this point. Additional patient-specific factors for SSI have been identified that are not included in this risk index, including the presence of anemia, blood transfusion intraoperatively, and colonization with resistant pathogens $[9,10]$. The SSI Risk Index warrants re-evaluation in view of these new findings, and the SIS as a society is uniquely equipped to lead this important effort.

\section{Prevention of Surgical Site Infections}

Preventive measures for SSI include timely antimicrobial prophylaxis, sterilization, proper ventilation of operating rooms, use of barriers, no shaving but rather clipping if hair removal is required, proper surgical skin preparation and surgical techniques, maintenance of normothermia and glycemic control, and provision of supplemental oxygen [11].

Division of Acute Care Surgery, Department of Surgery, University of Michigan, Ann Arbor, Michigan. 


\begin{tabular}{|l|l|l|}
\hline Year & Title of Presidential Address & SIS President \\
\hline 2008 & Staying Connected in Challenging Times & Stephen F. Lowry \\
\hline 2007 & Coming of Age & John C. Marshall \\
\hline 2006 & $\begin{array}{l}\text { Making Progress in an Enlightened Era: Opportunities } \\
\text { and Obstacles }\end{array}$ & Timothy R. Billiar \\
\hline 2005 & $\begin{array}{l}\text { Is the Glass Half Full or Half Empty? Thoughts on the } \\
\text { SIS and American Surgery }\end{array}$ & Edwin A. Deitch \\
\hline 2004 & I've Got Those Clinical Research Blues & Philip S. Barie \\
\hline
\end{tabular}

FIG. 1. Titles of previous presidential addresses.

The National Surgical Infection Prevention (SIP) project was the first component of the Surgical Care Improvement Project (SCIP). Initiated in 2003 by the Centers for Medicare and Medicaid Services (CMS) and the CDC, the SCIP partnership sought to reduce surgical mortality rates and morbidity substantially through collaborative efforts. Despite evidence of the effectiveness of preoperative antimicrobial agents for SSI prevention and the publication of guidelines for antimicrobial prophylaxis, it was recognized that use often was suboptimal. As part of the SIP initiative, three performance measures were developed:

Proportion of patients in whom intravenous (IV) antimicrobial prophylaxis is initiated within $1 \mathrm{~h}$ before incision;

Proportion of patients given prophylactic antimicrobials consistent with published guidelines; and

Proportion of patients whose antimicrobial prophylaxis is discontinued within $24 \mathrm{~h}$ after surgery.

The first report of the SIP Project baseline results, derived from a systematic random sample of 34,133 Medicare inpatients undergoing surgery in U.S. hospitals in 2001, documented that only $55.7 \%$ of patients received parenteral antimicrobial prophylaxis within $1 \mathrm{~h}$ before surgical incision. Antimicrobial agents were administered consistent with published guidelines to $92.6 \%$ of patients, but antimicrobial prophylaxis was discontinued within $24 \mathrm{~h}$ of surgery endtime in only $40.7 \%$ of patients. Interestingly, only $28 \%$ of these

Table 1. Factors Used in Calculation of SSI RisK by the National Healthcare Safety Network

Operation lasting more than the duration cut-point in hours, where the cut point is the 75th percentile of the duration of surgery in minutes for the procedure Contaminated (Class 3) or dirty/infected (Class 4) incision American Association of Anesthesiologists Class 3, 4, or 5 patients had prophylaxis in compliance with all three of these performance measures. It was concluded that "substantial opportunities exist to improve the use of prophylactic antimicrobials for patients undergoing major surgery" [12].

Where are we today with SSI prevention, and what does the future hold? We have made truly remarkable progress related to the SIP and SCIP initiatives nationwide. Substantial changes have been documented in the national performance for administration of antibiotics within $1 \mathrm{~h}$ before surgical incision, from $55.7 \%$ in 2001 to $91.6 \%$ in 2008 . Similarly, antimicrobial discontinuation within $24 \mathrm{~h}$ of surgery end-time increased from $40.7 \%$ in 2001 to $87.7 \%$ in 2008 (Fig. 2). It has become standard for hospitals to report their compliance with these SIP measures voluntarily, in part stimulated by pay-forreporting (Fig. 3). Additional efforts in achieving compliance with guideline recommendations for hair removal, glycemic control, and intraoperative normothermia are now under way. New methods to reduce SSI further, in addition to optimizing the SIP measures, are necessary; and a number of members of our organization are at the forefront of these advances.

\section{Challenges in SSI}

There are a number of persistent challenges in SSI, including resistant pathogens, our increasingly elderly population, more patients with chronic diseases or immunocompromised states having surgery, and larger numbers of patients undergoing solid organ transplantation or placement of prosthetic devices. We first reported that methicillin-resistant Staphylococcus aureus (MRSA) was the most common cause of SSI in vascular surgery patients ( $n=772$ over a two-year period) in 2004 [13]. Methicillin-resistant S. aureus has since emerged as the leading cause of postoperative infection in vascular surgery patients, and is associated with substantial morbidity, longer LOS, and higher incidences of amputation and graft removal. At that time, we advocated empiric MRSA antimicrobial cov- 


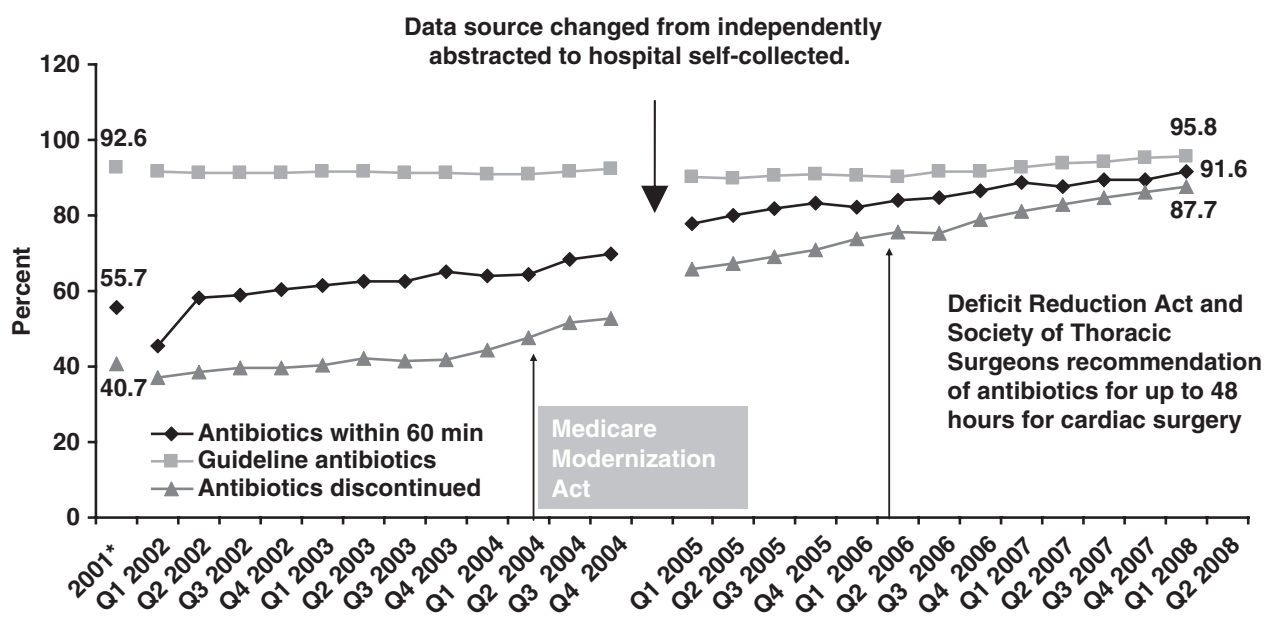

FIG. 2. Changes in National Performance for Perioperative Antibiotic Administration, baseline to first quarter, 2008, Surgical Infection Prevention (SIP) Project. *Baseline: National sample of 39,000 Medicare patients undergoing surgery in U.S. hospitals during 2001. From Bratzler [12]. Additional data provided by D Bratzler (2009).

erage for all patients with postoperative infections in vascular surgery, with de-escalation once cultures are available. Strategies to prevent MRSA SSI were recommended [14].

Where are we today? Comparison of the causative pathogens for SSI in U.S. hospitals (Fig. 4) documents that S. aureus increased from $22.5 \%$ (1986-2003) to 30\% (2006-2007), with MRSA now the leading causative pathogen, comprising $49.2 \%$ of all isolates $[15,16]$. In a study of 8,302 patients readmitted to U.S. hospitals from 2003-2007 with cultureconfirmed SSI, the proportion of infections caused by MRSA increased significantly, from $16.1 \%$ to $20.6 \%$, and these infections were associated with higher mortality rates, longer stays, and higher hospital costs [17]. In view of this important finding, some surgeons have advocated strongly that patients be screened for nasal carriage of MRSA prior to elective surgery, with modification of antimicrobial agents for SSI prevention on the basis of the results [18-20]. Eradication of
MRSA before surgery appears to lower the rates of SSI attributable to MRSA, and is recommended [21,22]. By contrast, a prospective interventional cohort study that employed a universal, rapid MRSA admission screening strategy among 21,754 surgical patients at a Swiss teaching hospital reported that nosocomial MRSA infection, including SSI, did not decrease. However, relatively low rates of MRSA infection were present at the start of this study, making it difficult to draw conclusions about the value of eradication [23].

Most recently, an "MRSA bundle" has been developed having five components: (1) Nasal screening of patients on admission, transfer, and discharge using polymerase chain reaction (PCR); (2) contact isolation of MRSA-positive patients; (3) standardized hand hygiene; (4) a cultural transformation campaign with staff and leadership engagement through positive deviance; and (5) continued monitoring of process and outcome measures. Implementation of the bundle

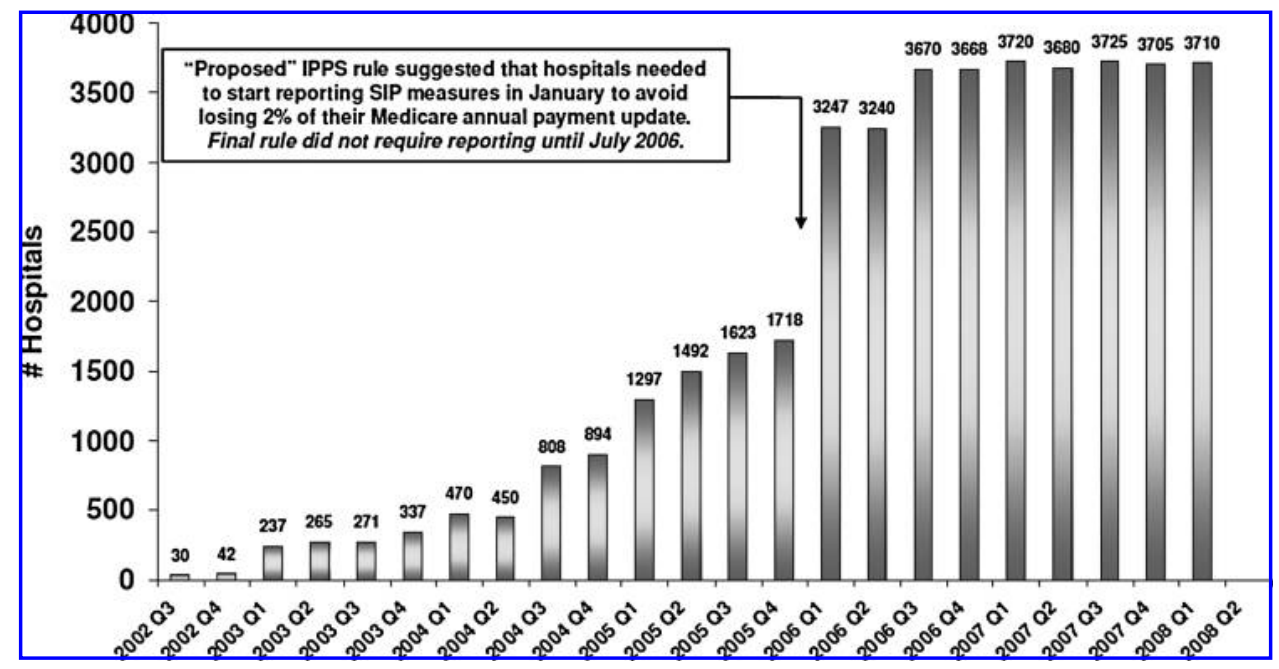

FIG. 3. Changes in number of reporting hospitals (voluntary) for perioperative antibiotic administration, baseline ${ }^{a}$ to first quarter, 2008, Surgical Infection Prevention (SIP) Project, showing impact of pay-for-reporting. *Baseline: National sample of 39,000 Medicare patients undergoing surgery in US hospitals during 2001. From: Bratzler DW et al. Arch Surg. 2005;140:174182. Additional data provided by D Bratzler, MD (2009). 


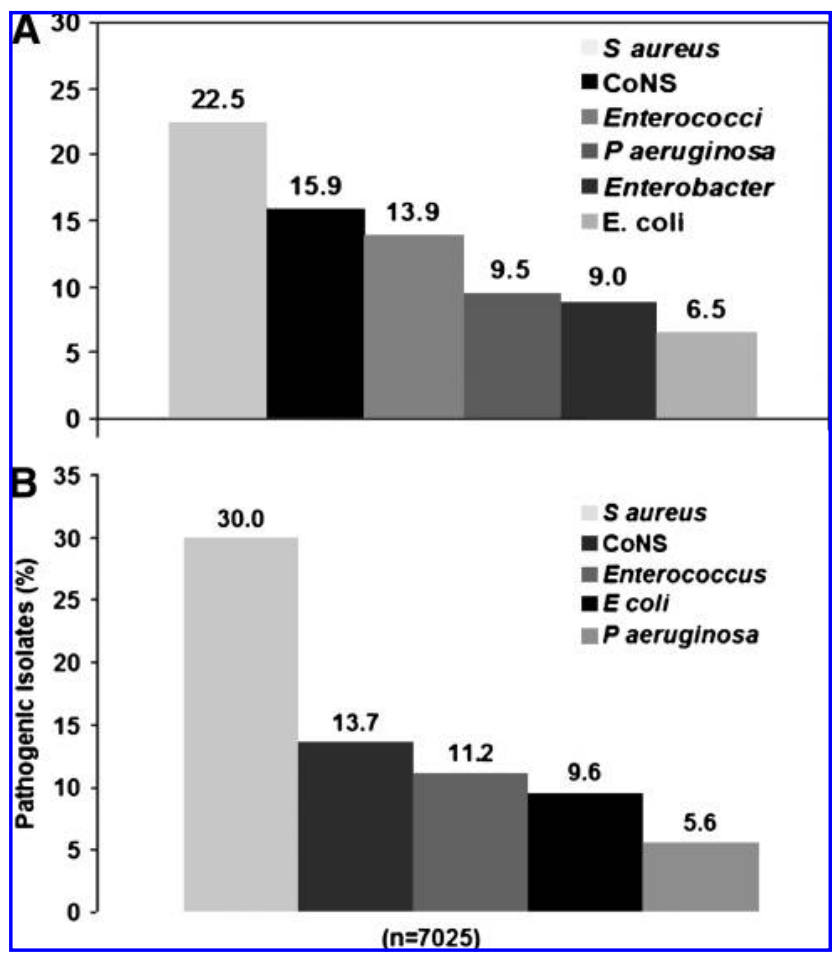

FIG. 4. Comparison of causative pathogens for surgical site infections in U.S. hospitals, 1986-2003 (A) vs. 2006-2007 (B). Staphylococcus aureus increased from $22.5 \%$ to $30 \%$ of all isolates, with methicillin-resistant $S$. aureus now the leading causative pathogen. (A) Pathogens isolated from 2,984 infections (National Nosocomial Infections Surveillance) 19862003. Staphylococcus aureus accounted for $22.5 \%$ of all isolates. The percentage of SSIs associated with gram-negative bacilli decreased from $56.5 \%$ in 1986 to $33.8 \%$ in 2003 . Reprinted from Gaynes R, Edwards JR. National Nosocomial Infections Surveillance System: Overview of nosocomial infections caused by gram-negative bacilli. Clin Infect Dis 2005;41:848854. (B) Pathogens isolated from 7,025 infections, 2006-2007 (National Healthcare Safety Network). Again, S. aureus was the most common pathogen $(n=2,108)$ with MRSA comprising 1,006 (49.2\%) of all isolates. Reprinted from Hidron AI, Edwards JR, Patel J, et al; National Healthcare Safety Network Team; Participating National Healthcare Safety Network Facilities. NHSN Annual Update: Antimicrobialresistant pathogens associated with healthcare-associated infections: Annual summary of data reported to the National Healthcare Safety Network at the Centers for Disease Control and Prevention, 2006-2007. Infect Control Hosp Epidemiol 2008;29:996-1011. CoNS = coagulase-negative staphylococci.

was associated with a significant decrease in MRSA transmission, from 5.8 to 3.0 per 1,000 bed-days; a significant reduction in MRSA nosocomial infections, from 2.0 to 1.0 per 1,000 bed-days; and a significant decrease in overall SSIs, with a $65 \%$ reduction in orthopedic MRSA SSIs and a $1 \%$ decrease in cardiac MRSA SSIs [24].

The advent of community-associated MRSA (CAMRSA)[25,26] has impacted SSI significantly. Recent studies document that CA-MRSA is replacing traditional healthcareassociated or nosocomial MRSA strains in SSI among inpatients [27]. A report from a large community hospital in St. Louis examined the rates of SSI attributable to S. aureus in a total of 122,040 surgical procedures in 2003-2006 vs. 2006-
2007. The identified pathogen was MRSA in $40 \%$ of all inpatients in both time periods. Interestingly, the percentage of clindamycin-susceptible MRSA (distinguishing CA-MRSA) as a causative pathogen for inpatients increased from $9 \%$ in the early period to $19 \%$ in the later period. This increase was observed only among inpatients (relative risk [RR] 2.2, 95\% confidence interval [CI] 1.3, 3.8; $\mathrm{p}=0.007)$, not among ambulatory patients. Similarly, CA-MRSA has emerged as a leading cause of healthcare-associated infections among patients with prosthetic joint SSIs [28].

\section{Skin and Soft Tissue Infections}

The increasing prevalence of MRSA as the predominant cause of skin and soft tissue infections (SSTIs) presenting to the emergency department is well known, with most related to CA-MRSA as the causative pathogen [29-33]. Community-associated MRSA has been documented as a pathogen in severe SSTIs, including necrotizing soft tissue infections (report of 14 patients with monomicrobial MRSA; 40\% had concomitant bacteremia) [34] and pyomyositis [35-37]. The emergence of CA-MRSA as causative pathogens in nosocomial skin infections in burn and trauma units has been reported recently [38]. Clearly, there is no question that the line between community-associated and healthcareassociated MRSA strains as causes of SSTIs is becoming increasingly blurred. This has spurred the development of a more complicated classification system for MRSA infections that separates healthcare-associated infections into "community-onset" or "hospital-onset" (Table 2), making the future epidemiologic study of these infections far more complex [26].

But we also recognize that pan-sensitive pathogens can cause severe necrotizing soft-tissue infections. Future study of the pathogenesis and prevention of these life-threatening infections is warranted, and the SIS is poised to perform multicenter clinical and translational studies in this important area. The SIS Guidelines for the Treatment of Complicated Skin and Soft Tissue Infections, published by the Therapeutics and Guidelines Committee, present an evidence-based summary of our current knowledge [39].

\section{Complicated Intra-abdominal Infections}

The past leaders of the SIS have defined the importance of "source control" for adequate treatment of abdominal sepsis, in addition to antimicrobial management and appropriate resuscitation. The principal therapy for "source control" is removal: Resection of an infected organ (appendix, gallbladder), debridement of necrotic tissue (necrotizing pancreatitis), resection of ischemic bowel, repair/resection of intestinal perforation, and surgical or radiologic drainage of abscess. However, the severity and impact of complicated intraabdominal infections can be profound, even with appropriate source control procedures.

We recently admitted to our surgical intensive care unit (ICU) a 34 year-old woman with a history of asthma but no other co-morbidities. She presented to an emergency department with right lower-quadrant abdominal pain, and a computed tomography (CT) scan confirmed acute appendicitis. Ampicillin-sulbactam was administered intravenously as empiric antimicrobial therapy, and she underwent open 
Table 2. Definition of Healthcare-Associated Infections

\begin{tabular}{ll}
\hline Classification & \multicolumn{1}{c}{ Definition } \\
\hline $\begin{array}{l}\text { Healthcare-associated } \\
\text { Community-onset }\end{array}$ & $\begin{array}{l}\text { Cases with at least one of the following risk factors: } \\
\text { (1) Presence of an invasive device at time of admission }\end{array}$ \\
(2) History of infection or colonization with methicillin-resistant Staphylococcus aureus \\
(3) History of surgery, hospitalization, dialysis, or residence in a long-term care \\
facility in 12 mos preceding culture date
\end{tabular}

Reprinted from Klevens et al. [26].

appendectomy at a referring hospital. Postoperatively, she developed severe hypoxemia, septic shock necessitating multiple vasopressors, and multiple organ dysfunction consistent with a diagnosis of toxic shock syndrome. She was transferred to the University of Michigan for an extracorporeal membrane oxygenation evaluation because of severe acute respiratory distress syndrome. Her empiric antimicrobial agents were broadened to imipenem-cilastatin, vancomycin, and clindamycin. She was resuscitated, and her hypoxemia was treated with high-frequency oscillatory ventilation. Continuous veno-venous hemofiltration was initiated because of acute renal failure. Norepinephrine and vasopressin were used for treatment of profound vasodilatory shock. Activated protein $C$ and low-dose corticosteroids were administered for septic shock. Appendix and blood cultures confirmed Group A Streptococcus, sensitive to all the antimicrobial agents tested. She recovered fully, with an ICU LOS of 40 days and a hospital LOS of 50 days.

But the story did not end there. An older sister, who visited our patient in the surgical ICU, returned home to Florida and there developed pneumonia necessitating mechanical ventilation and ICU admission. Bronchoalveolar lavage cultures confirmed Group A Streptococcus. Later, the patient's youngest daughter, three years old, developed pain in her knee and was evaluated at a local community hospital. Her knee effusion was aspirated, and the culture grew Group A Streptococcus. The far-reaching effects of this case of communityacquired appendicitis were remarkable and confirm for us that we do not understand fully the mechanisms of pathogenicity and the relations of host and pathogen in surgical infections, even of antibiotic-susceptible organisms and their associated toxins.

Intra-abdominal infections attributable to specific pathogens can be particularly problematic. Clostridium difficile colitis is the predominant hospital-acquired gastrointestinal infection in the U.S., and an important nosocomial cause of morbidity and death. Recently, several C. difficile colitis outbreaks caused by one strain, PCR ribotype 027 (NAP1/027), associated with increased disease and a higher risk of death (mortality rate of $25 \%$ in patients with white blood cell counts $>20.0 \times 10^{9} /$ microliter), have been reported in North America and several European countries [40]. This strain is toxin A/toxin B positive, contains the gene for binary toxin $(c d t B)$, and has an 18-basepair deletion and a frameshift mutation in the gene $t c d C$, hypothesized to result in deregulated expression of toxins A and B. The NAP1/027 strain is hypervirulent, and these organisms produce far more toxin in vitro than other toxinotypes, ranging from 16to 23-fold higher [41]. It has been documented by multivariable analysis that patients infected with ribotype 027 are twice as likely to die within 30 days of diagnosis than are patients infected with other ribotypes (adjusted odds ratio [OR] 2.06; 95\% CI 1.00, 4.22) [42]. In surgical patients, the incidence of $C$. difficile increased significantly (34\% higher than in 2001) from $0.52 \%(8,113$ of $1,553,597$ inpatients undergoing a surgical procedure) and was most prevalent after emergency operations and among patients having intestinal resections [43]. Independent risk factors for C. difficile infection include perioperative antimicrobial prophylaxis, older age, and administration of cefoxitin (rather than cefazolin) alone or in combination with another drug [44]. Total abdominal colectomy and end-ileostomy remain the procedure of choice for patients with severe or refractory $C$. difficile colitis, but even with surgery, mortality rates are high, ranging from $35 \%$ to $65 \%$ [ $45-47]$.

The treatment of infected necrotizing pancreatitis is another area of change. The traditional open surgical necrosectomy has shifted toward minimally invasive endoscopic, radiologic, and laparoscopic approaches, including minimally invasive retroperitoneal pancreatic necrosectomy [48-50], with which a body of evidence demonstrates that acceptable outcomes can be achieved [51]. What are the appropriate indications for open vs. minimally invasive necrosectomy? What is the ideal technique? What is the ideal time to offer these techniques, and what parameters predict successful outcomes? These questions warrant additional study, and the members of our organization who have led other trials in this important area of pancreatitis management are ready to participate [52-55]. A re-evaluation of the terminology for standardization of the reporting and description of peripancreatic collections in acute pancreatitis is necessary, and SIS should participate in this international effort.

The SIS has a number of issues to address in the very important area of intra-abdominal infections. These include whether to administer antibiotics as sole therapy for appendicitis vs. surgical intervention; the timing of surgical intervention for diverticulitis, especially in younger patients; determination of the optimal therapy for peritonitis and infected pancreatitis-single intervention vs. staged serial procedures; and definition of the adequacy of source control in clinical trials in complicated intra-abdominal infections. 


\section{Nosocomial (Hospital-acquired) and Healthcare-associated Infections}

Ventilator-associated pneumonia (VAP) and CR-BSI are common nosocomial infections in surgical patients, and many members of the SIS have helped to advance knowledge of these subjects. The recent recognition of potentially antibioticresistant infections occurring in healthcare settings outside the hospital (e.g., skilled nursing facilities) in patients with specific risk factors has resulted in the formulation of the category of "healthcare-associated infections" [56]. Implicit in the definition of these infections is that patients will require initial broad-spectrum antimicrobial therapy to cover possible multi-drug-resistant (MDR) pathogens, in contrast to patients with community-acquired infections.

\section{Ventilator-associated pneumonia}

Reports from NNIS and NHSN have documented a recent decline in VAP rates in the U.S. related to the implementation of prevention strategies. However, the highest rates of VAP remain in surgical ICUs, particularly in burn and trauma ICUs (Table 3) [57-59]. We have focused on implementing all evidence-based strategies to reduce VAP in our ICUs using two fundamental methods: (1) decreasing aspiration incidence (by positioning, keeping the head of the bed elevated, and the use of continuous aspiration of subglottic secretions [CASS] endotracheal tubes); and (2) reducing bacterial colonization with ventilator weaning protocols, topical chlorhexidine use in the posterior pharynx, and the use of silver-coated endotracheal tubes [60].

The microbiology of VAP has changed significantly over the past decade (Fig. 5). During 1992-1999, S. aureus and Pseudomonas aeruginosa were the two leading causative pathogens for VAP and hospital-acquired pneumonia, each organism representing approximately $18 \%$ of all isolates. Enterobacter spp. and Klebsiella pneumoniae were less common, comprising $12 \%$ and $7 \%$ of VAP isolates, respectively $[61,62]$. The most recent NHSN report of 2006-2007 data from U.S.

Table 3. Recent Decline in Cases of Ventilatorassociated Pneumonia Per 1,000 Ventilator Days in Intensive Care Units (ICUs) in the United States. Note Higher Rates in Surgical and Neurosurgical ICUs and Highest RATES IN BURN AND Trauma ICUs

\begin{tabular}{lccc}
\hline Type of ICU & $\begin{array}{c}\text { 2004 Pooled } \\
\text { means }\end{array}$ & $\begin{array}{c}\text { 2006 Pooled } \\
\text { means }\end{array}$ & $\begin{array}{c}\text { 2007 Pooled } \\
\text { means }^{3}\end{array}$ \\
\hline Burn & $\mathbf{1 2 . 0}$ & $\mathbf{1 2 . 3}$ & $\mathbf{1 0 . 7}$ \\
Cardiothoracic & 7.2 & 5.7 & 4.7 \\
Coronary & 4.4 & 2.8 & 2.5 \\
Medical & 4.9 & 3.1 & 2.5 \\
Medical-surgical & & & \\
$\quad$ Major teaching & 5.4 & 3.6 & 3.3 \\
$\quad$ hospital & & & \\
$\quad$ All others & 5.1 & 2.7 & 2.3 \\
Neurosurgical & 11.2 & 7.0 & 6.5 \\
Pediatric & 2.9 & 2.5 & 2.1 \\
Surgical & 9.3 & 5.2 & 5.3 \\
Trauma & $\mathbf{1 5 . 2}$ & $\mathbf{1 0 . 2}$ & $\mathbf{9 . 3}$ \\
\hline
\end{tabular}

\footnotetext{
${ }^{1}$ National Nosocomial Infections Surveillance System [57]

${ }^{2}$ Edwards et al. [58].
}

${ }^{3}$ Edwards et al. [59].

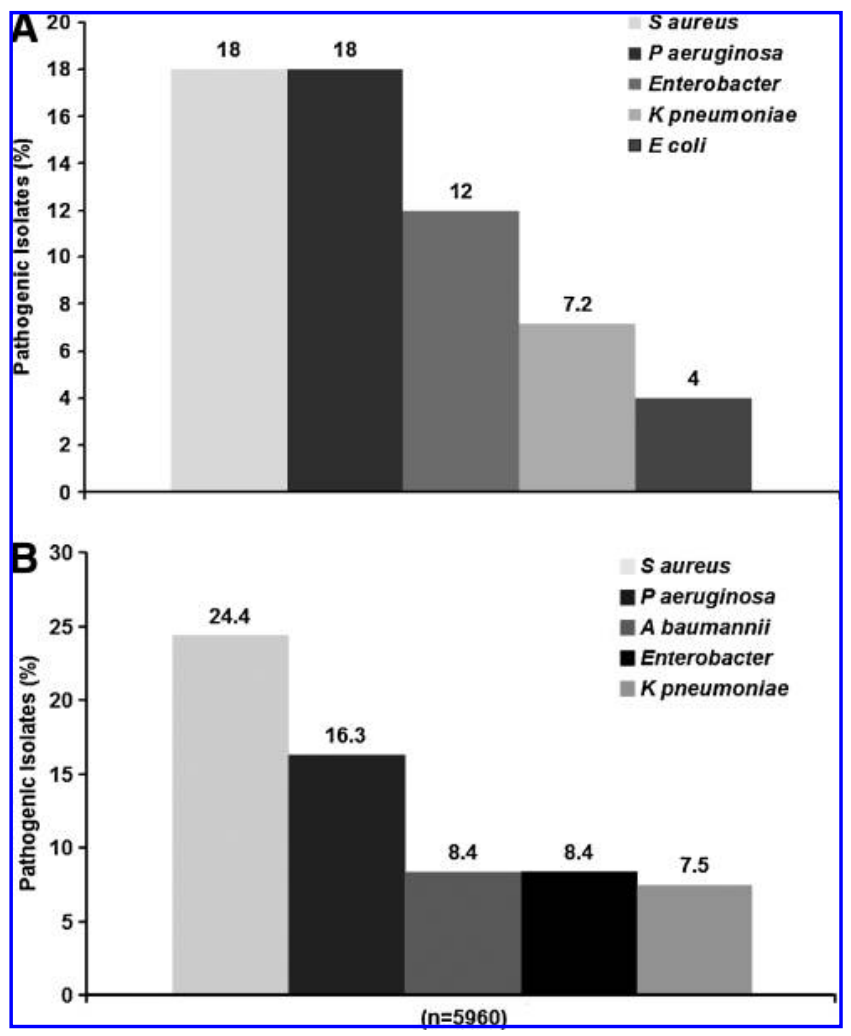

FIG. 5. Causative pathogens for ventilator-associated pneumonia in U.S. hospitals, 1992-1999 (A) vs. 2006-2007 (B). Staphylococcus aureus increased from $18 \%$ to $24.4 \%$. Methicillin-resistant $S$. aureus is now the leading causative pathogen, comprising $54.4 \%$ of all $S$. aureus isolates. Reprinted from Hidron AI Edwards JR, Patel J, et al; National Healthcare Safety Network Team; Participating National Healthcare Safety Network Facilities. NHSN Annual Update: Antimicrobial-resistant pathogens associated with healthcare-associated infections: Annual summary of data reported to the National Healthcare Safety Network at the Centers for Disease Control and Prevention, 2006-2007. Infect Control Hosp Epidemiol 2008;29:996-1011.

hospitals confirms a significant change [16]. The leading pathogen is now $S$. aureus, representing $24.4 \%$ of all isolates, but as $54.4 \%$ of all these are methicillin resistant, MRSA is the single leading VAP pathogen. Pseudomonas aeruginosa decreased from $18 \%$ to $16.3 \%$, and Enterobacter decreased from $12 \%$ to $8.4 \%$. Strikingly, Acinetobacter baumannii is now the third most common VAP pathogen, comprising $8.4 \%$ of all isolates. This MDR pathogen is difficult to eradicate and is a major problem for infection control in ICU and hospital environments.

Increasing multi-drug resistance also has been identified in $S$. aureus strains that cause pneumonia. A group in France demonstrated the emergence and spread of a new isolate of MRSA in cystic fibrosis patients that probably was selected by antibiotic pressure. This isolate expressed an MDR, heteroglycopeptide-intermediate resistance $S$. aureus (GISA) phenotype, and transmission electron microscopy revealed abnormalities of cell-wall thickness as well as aberrant septation. Genomic analysis of this MDR strain revealed an antibiotic-inducible bacteriophage [63]. Its induction may result in high-frequency transfer and promotion of the spread 
of virulence or antibiotic resistance determinants. The emergence of well-adapted MRSA is worrisome in such a population, which is chronically colonized and receiving many antibiotics, and represents a model for the emergence of uncontrollable "super bugs" in a specific niche.

"Adequate" antimicrobial therapy (defined as use that covers causative pathogens) is associated with better outcomes in empiric treatment of VAP, and MDR pathogens are independent risk factors for inadequate therapy [64]. This finding has resulted in the need to use broad-spectrum antimicrobial agents with mandatory anti-MRSA treatment in patients with VAP, and waiting 2-3 days for culture results to institute proper drug de-escalation.

Early, accurate diagnosis is fundamental in the management of patients with VAP; however, the definition of VAP remains a difficult challenge [65]. Most ICUs currently use the CDC clinical definition; however, in a recent ICU study, the accuracy of this definition compared with autopsy findings was poor [66]. Given the severity of VAP and the high prevalence of serious conditions that can mimic VAP, additional tests that provide further evidence for VAP clearly are warranted [67]. At present, no sensitive and specific biomarker is available to confirm the diagnosis. C-Reactive protein, procalcitonin, and soluble triggering receptor expressed on myeloid cells (sTREM-1) have been evaluated as biomarkers for VAP. Multiple studies have confirmed that the first two have poor diagnostic accuracy [68-70].

The TREM-1 is a member of the immunoglobulin superfamily, and its expression on phagocytes is upregulated by microbial products. Preliminary studies documented that higher concentrations of sTREM-1 in bronchoalveolar lavage fluid differentiated the presence vs. absence of VAP $(n=148$; 46 patients with confirmed VAP). The presence of sTREM-1 by itself was more accurate than any clinical finding or laboratory value in identifying the presence of pneumonia (likelihood ratio 10.38; sensitivity 98\%, specificity $90 \%$ ). In multiple logistic regression analysis, the presence of sTREM-1 was the strongest independent predictor of pneumonia (OR 41.5) [71]. Plasma concentrations of sTREM-1 were not diagnostic [72]. Unfortunately, more recent studies have not confirmed these preliminary results $[73,74]$. Most recently, circulating leukocyte RNA profiles or "riboleukograms" have been documented to detect VAP after blunt trauma $(n=158)$ four days before clinical diagnosis with a sensitivity of $57 \%$ and a specificity of $69 \%$ [75]. These interesting findings warrant validation in prospective trials.

Necrotizing pneumonias are an increasing problem associated with a higher mortality rate in critically ill patients. The responsible pathogens include Pseudomonas spp. and MRSA. Concurrent with the emergence of CA-MRSA, there have been several reports of community-acquired necrotizing pneumonia in young otherwise-healthy patients, some following a viral prodrome and influenza infection [76,77]. In the most recent report from the CDC of 51 cases of community-acquired $S$. aureus pneumonia, the median age was 16 years, and $44 \%$ had no co-morbidities. Influenza was confirmed in $33 \%$ of the cohort, and $91 \%$ of these patients died. Superinfection with MRSA was confirmed in 37 of the 51 patients, and $48 \%$ died. Empiric coverage of MRSA pneumonia was provided to only $43 \%$ of these patients [78].

Concomitant use of antibiotics that suppress toxin production has been advocated for the treatment of severe and invasive CA-MRSA infections, including pneumonia. The rationale for their use in CA-MRSA pneumonia includes the presumed role of the Panton-Valentine leukocidin (PVL) toxin, which is associated with tissue necrosis [79], and the high morbidity and mortality rates. Some investigators have advocated treatment of patients with MRSA pneumonia with agents that suppress toxin production (e.g., clindamycin, linezolid) and urge the avoidance of those (i.e., $\beta$-lactams) that can increase production of PVL and other exotoxins [80].

Finally, a hypothesis has emerged of "ventilator-associated tracheobronchitis" (VAT), developing from tracheal colonization in intubated and mechanically ventilated patients, which can lead to VAP [81]. Recent data suggest that VAT may be an important modifiable risk factor for VAP and that targeted antimicrobial therapy for VAT may be a new paradigm for VAP prevention and better patient outcomes [82-84].

\section{Catheter-associated blood stream infection}

Reports from NNIS and NHSN have documented a recent decline in CA-BSI rates in the U.S. related to the implementation of preventive strategies. It should be noted, however, that, as is the case with VAP, the highest rates of CA-BSI are in trauma and burn ICUs (Table 4)[57-59]. The critical care group at the Johns Hopkins Medical Institutions first documented their ability to eliminate CR-BSIs in the ICU using a "recipe for zero CR-BSI," including (1) standardized education of staff; (2) standardized placement of central venous catheters (CVC)s; (3) CVC carts with all supplies; (4) daily inquiry regarding the possibility of discontinuation of CVCs; (5) a CVC-insertion checklist for assurance of aseptic technique; and (5) empowering the staff to halt the procedure if aseptic technique has been violated [85]. By the authors' report, this practice prevented as many as $43 \mathrm{CR}$-BSIs, eight (95\% CI 0, 15) deaths, and $\$ 1,945,922$ (95\% CI $\$ 1,483,844$, $\$ 2,408,000)$ in additional costs per year.

We have gone back to the basics of hand hygiene and strict aseptic technique to prevent this hospital-associated infection. A similar strategy was employed in the Michigan Keystone

Table 4. Recent Decline in Catheter-Related Blood Stream Infection Cases Per 1,000 Catheter Days in InTENSive Care Units (ICUs) IN THE United States. Note Highest Rates in Burn and Trauma ICUs

\begin{tabular}{lccc}
\hline Type of ICU & $\begin{array}{c}\text { 2004 Pooled } \\
\text { means }\end{array}$ & $\begin{array}{c}\text { 2006 Pooled } \\
\text { means }\end{array}$ & $\begin{array}{c}\text { 2007 Pooled } \\
\text { means }^{3}\end{array}$ \\
\hline Burn & 7.0 & 6.8 & 5.6 \\
Cardiothoracic & 2.7 & 1.6 & 1.4 \\
Coronary & 3.5 & 2.8 & 2.1 \\
Medical & 5.0 & 2.9 & 2.4 \\
Medical-surgical & & & \\
$\quad$ Major teaching & 4.0 & 2.4 & 2.0 \\
$\quad$ All others & 3.2 & 2.2 & 1.5 \\
Neurosurgical & 4.6 & 3.5 & 2.5 \\
Pediatric & 6.6 & 5.3 & 2.9 \\
Surgical & 4.6 & 2.7 & 2.3 \\
Trauma & 7.4 & 4.6 & 4.0 \\
\hline
\end{tabular}

\footnotetext{
${ }^{1}$ National Nosocomial Infections Surveillance System [57].

${ }^{2}$ Edwards et al. [58].

${ }^{3}$ Edwards et al. [59].
} 
Project, a state-wide intervention to decrease CA-BSIs in the ICU [86]. The Keystone Intervention also employed five evidence-based procedures: (1) Hand hygiene; (2) full barrier precautions during CVC insertion; (3) chlorhexidine preparation of the insertion site; (4) avoidance of the femoral vein as an insertion site; and (5) removal of all unnecessary CVCs whenever possible. The results of this statewide effort were remarkable: A $66 \%$ reduction in CA-BSIs from baseline was noted in each hospital. We are proud of our long-term results in the University of Michigan surgical ICU, where we documented zero CR-BSIs from January 2006 through September 2008.

Just as with VAP, significant changes have been identified in the microbiology of CR-BSI in U.S. hospitals (Fig. 6). Coagulase-negative staphylococci remain the most common pathogen. In the NNIS report spanning 1986-2003, the next most common pathogens were $S$. aureus and enterococci, representing $14.3 \%$ and $14.5 \%$ of isolates, respectively. In the most recent report from NHSN (2006-2007), enterococci and Candida spp. were the next most common, representing $16.0 \%$ and $11.7 \%$ of pathogens, respectively. These figures document a significant increase in Candida as causative pathogens for CR-BSI and conversely, a significant reduction in $S$. aureus isolates in the most recent period (from $14.3 \%$ to $9.9 \%$ of all pathogens). Interestingly, a recent study documented that although total hospital-onset MRSA blood stream infection rates were relatively stable for the period 2000-2006, CAMRSA strains were responsible for an increasing proportion of cases (from $24 \%$ to $49 \%$ ), suggesting replacement of traditional hospital-associated strains [87]. The ICU had the highest rate of increase of community genotypes, from $5 \%$ in the first period (2000-2003) to $17 \%$ in the second period (20032006). The rate of increase in the community genotype in the hospital was from $5 \%$ to $10 \%$. Ongoing surveillance of changes in the microbiology of CA-BSI and continued efforts at prevention are warranted.

\section{Acute Care Surgery}

The last issue I am addressing is most important: Who will care for patients with surgical infections in the future? As you are all aware, a new specialty of "acute care surgery" is emerging to fill the void left by those general surgeons who do not wish to participate. The group at the University of Pennsylvania reported that their acute care surgery model with an in-house on-call faculty improved the outcomes of patients with appendicitis $(n=298)$, with significant reductions in the time from consult to the operating room $(7.6 \mathrm{vs} .3 .5 \mathrm{~h} ; \mathrm{p}<0.05)$ and the appendiceal rupture rate $(21.1 \%$ to $12.3 \% ; \mathrm{p}=0.05)$, no difference in negative appendectomy rate, and a significantly lower complication rate $(17.4 \%$ vs. $7.7 \%$; $<<0.05)$ and hospital LOS (3.5 vs. 2.3 days; $\mathrm{p}<0.001)$ [88].

At the University of Michigan, we recently reorganized to create a Division of Acute Care Surgery (ACS) with four components: Trauma Surgery (Director: Lena Napolitano); Burn Surgery (Director: Stewart Wang); Surgical Critical Care (Co-Directors: Lena Napolitano and Pauline Park); and NonTrauma Emergency (NTE) Surgery (director to be named). In the past, we had a separate Division of Trauma-Burn Surgery under the leadership of Doctor Paul Taheri, and surgical critical care was separate under the leadership of Doctor Robert Bartlett. At present, we have a unified division with

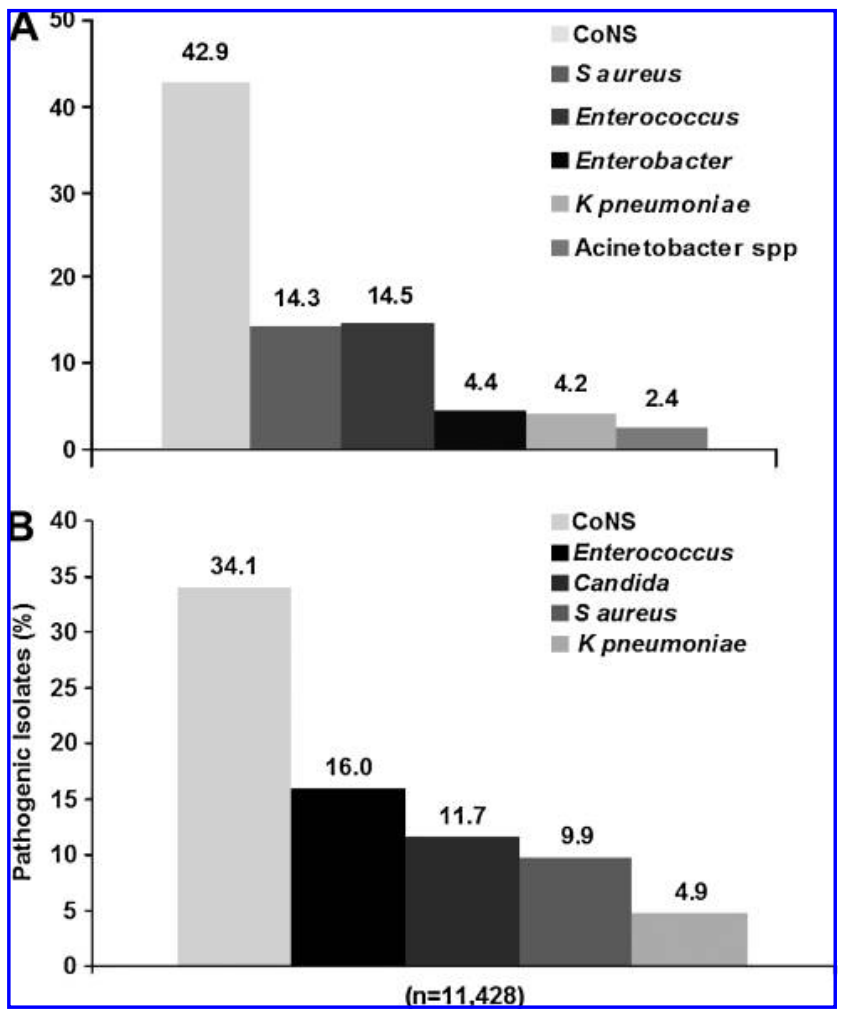

FIG. 6. Comparison of causative pathogens for catheterrelated blood stream infections in U.S. Hospitals, 1986-2003 (A) vs. 2006-2007 (B). Staphylococcus aureus increased from $22.5 \%$ to $30 \%$, with methicillin-resistant S. aureus now the leading causative pathogen. (A) Pathogens isolated in 19862003 (National Nosocomial Infections Surveillance). Coagulase-negative staphylococci (CoNS) were the most common, comprising $42.9 \%$ of all isolates. Reprinted from Gaynes R, Edwards JR. National Nosocomial Infections Surveillance System: Overview of nosocomial infections caused by gramnegative bacilli. Clin Infect Dis 2005;41:848-854. (B) Pathogens isolated in 2006-2007 (National Healthcare Safety Network). Again, coagulase-negative staphylococci were the most common, comprising $34.1 \%$ of all isolates. Reprinted from Hidron AI, Edwards JR, Patel J, et al; National Healthcare Safety Network Team; Participating National Healthcare Safety Network Facilities. NHSN annual update: Antimicrobial-resistant pathogens associated with healthcare-associated infections: Annual summary of data reported to the National Healthcare Safety Network at the Centers for Disease Control and Prevention, 2006-2007. Infect Control Hosp Epidemiol 2008;29:996-1011.

nine faculty members; eight surgeons are certified in critical care by the American Board of Surgery. The clinical services we cover are trauma and burn surgery, general surgery, and surgical critical care (Surgical, Trauma-Burn, and Cardiovascular ICUs).

In July 2005, under the leadership of Doctor Gerald Doherty as section chief of General Surgery, we established the NTE Service, responsibility for which is shared by the General Surgery and ACS faculties. One surgeon faculty member covers one week at a time. The NTE team includes a surgical chief resident, a post-graduate year (PGY)-3 resident, a PGY-1 resident, and two physician assistants. This service manages all urgent and emergency general surgery 


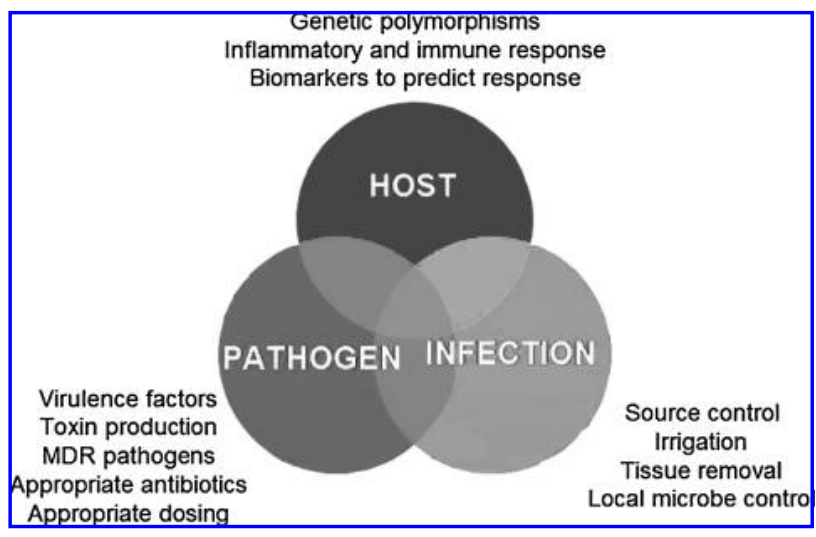

FIG. 7. Surgical infections: Interplay of host, pathogen, and specific infection factors.

patients, such as those with enterocutaneous fistula, open abdomen, or complications of prior surgical interventions, as well as the commonplace general surgery cases of hernias, appendicitis, cholecystitis, pancreatitis, diverticulitis, or SSTI. In effect, our NTE service cares for patients with acute surgical infections.

The challenging and complex cases seen on our NTE service are myriad and included the following during my week on the service: a morbidly obese patient with an incarcerated hernia and small-bowel obstruction following three hernia repairs, a new patient with enterocutaneous fistulae, a bone marrow transplant patient with neutropenic enterocolitis, a lung transplant patient (three months postoperative) with perforated diverticulitis and fecal peritonitis, a young patient with upper gastrointestinal hemorrhage secondary to a metastasis from Burkitt lymphoma in the fourth portion of the duodenum that necessitated duodenal resection for hemorrhage control, and a patient with a perforated small bowel secondary to multiple large melanoma metastases in the abdomen. Approximately $45 \%$ of our NTE patients require admission to the ICU, and they are older, have higher acuity as measured by Acute Physiology and Chronic Health Evaluation III score, require longer ICU and hospital LOSs and longer duration of mechanical ventilation, and have higher ICU and hospital mortality rates than our non-NTE surgical ICU patients [89].

In reality, there is a crisis looming. Acute surgical care in particular is threatened by a decline in the number of surgeons performing these emergency general procedures, whereas the volume and complexity of these cases continues to increase [90]. Acute care surgery, inclusive of trauma, surgical critical care, and emergency general surgery, is poised to make a difference for our patients with surgical infections. Our identity as acute care surgeons can be summarized as "Access, Expert, Available-for the best care of our patients."

The SIS must play a leadership role in acute care surgery. An ad hoc Committee of Acute Care Surgery was created by past-president Doctor John Marshall, and it will be important for this committee to work closely with the Acute Care Surgery Committee of the American Association for the Surgery of Trauma (AAST), the organization leading the acute care surgery fellowship effort at present. In particular, I have asked this SIS committee to take responsibility for the development of a surgical infections curriculum for training of acute care surgery fellows and to work with AAST to standardize this as a national curriculum.

\section{SIS: Future Challenges and Opportunities}

In the words of John Marshall at our $27^{\text {th }}$ Annual Meeting in 2007, "Our survival as an organization will hinge on the following: Our willingness to review critically our successes and failures; our exploration of partnerships and common activities with like-minded societies; and our leadership in new initiatives in the understanding and management of infection [91]."

Surgical infections pose complex issues related to the host, the pathogen, and the specific infection that results (Fig. 7). We, as the SIS, must evaluate these three areas critically in an effort to create a positive impact on the field of surgical infections. This will require the conduct of basic science investigations to

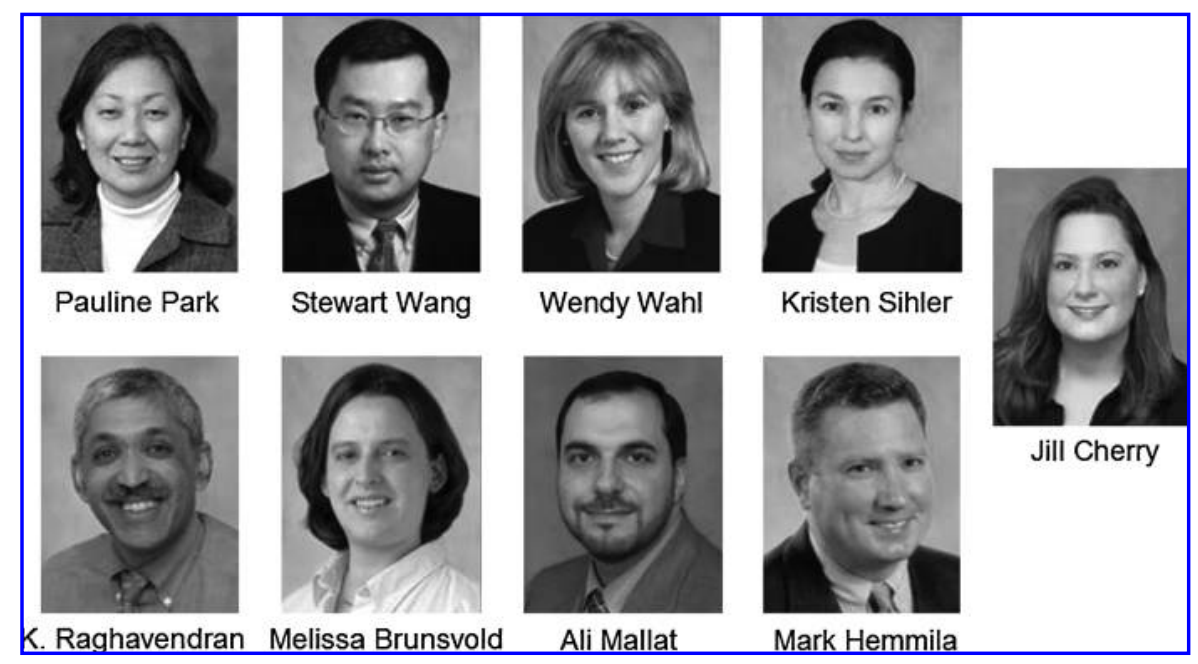

FIG. 8. Faculty of the Division of Acute Care Surgery (Trauma, Burn, Surgical Critical Care, Emergency Surgery), University of Michigan. 
examine pathogen issues, including virulence factors, toxin production, and effective antimicrobial agents. Clinical and translational studies are necessary to explore genetic, inflammatory, and immune factors and biomarkers to define diseases and examine host responses, and to develop new strategies for the prevention and treatment of surgical infections.

The SIS is poised to make great advances in multiple areas in the field of surgical infections. The Scientific Studies Committee, led by Doctor Sam Arbabi, is contemplating the development of an acute care surgery registry. This would advance our knowledge of acute surgical infections greatly. The development of a surgical infections curriculum for the acute care surgery fellowship would represent a great advance, and collaboration with our SIS-Europe colleagues who developed the Internet Course on Surgical Infections $\left(5^{\text {th }}\right.$ Edition, 2009; www.surgicalinfections.org) is continuing. Guideline development, under the leadership of Doctor Addison May as Chair of the Therapeutics and Guidelines Committee, has made major advances this year. We have published the SIS Guidelines for the Treatment of Complicated Skin and Soft Tissue Infections [39] and the first Joint SIS/IDSA Guideline under the direction of Doctors John Mazuski (SIS Chair) and Joseph Solomkin (Infectious Diseases Society of America [IDSA] Chair) entitled "Diagnosis and Management of Complicated Intra-Abdominal Infections in Adults and Children: Guidelines by the Surgical Infection Society and the Infectious Diseases Society of America" [92]. An update of the Guidelines on Antimicrobial Prophylaxis in Surgery is in progress in conjunction with the American Society of Health-System Pharmacists, SIS, IDSA, and the Society of Healthcare Epidemiologists of America (the SIS representatives are Doctors E. Patchen Dellinger, Robert Sawyer, and Lena Napolitano).

We can accomplish great things only with teamwork. Everyone must do his or her part. The focus must be on the surgical patient. Innovative thinking and expert scientific investigation are required to move our field forward. Mentorship is of vital importance to our Society, as we shepherd our trainees and junior faculty in the field of surgical infection. The future goals of the SIS must be clear, and we must commit to them with passion and perserverance. We, as the Surgical Infection Society, can contribute greatly to the field of surgical infections for the future.

\section{Acknowledgments}

Finally, I offer my sincere thanks to the many individuals who have helped me in my surgical career and my life. First, my thanks and love to my family, which has always supported me in my endeavors. Carmine and Mary, my parents-the "old folks" - provided a foundation of support and education, and continue to lead our family. To my brother, Angelo, and his family, his wife Liz and my niece and nephew Sophia and Carmen Peter (C.P.) — they keep me grounded in life. We are very excited to have an Italian wedding this year with my nephew Carmen bringing his fiancée Lauren into our family (http://carmenandlauren.com).

I owe a world of thanks to my mentors in surgery, who guided me into a career of trauma and surgical critical care. My mentors at the University of North Carolina-Chapel Hill during my trauma/critical care fellowship years were Doctors Anthony Meyer, George Sheldon, and Christopher
("Chip") Baker. I was fortunate to be a part of that dynamic and committed group of individuals devoted to the academic development of trauma, critical care, and general surgery.

Doctor Mitchell Fink provided me with the wonderful opportunity to join him at the University of Massachusetts in my first faculty position when he served as Division Chief. Three years later, I was recruited to the University of Maryland by Doctors Barbara Bass and Anthony Imbembo and spent ten years at the University of Maryland Medical Center and the R. Adams Cowley Shock Trauma Center as Surgical Critical Care Fellowship Program Director. My greatest thanks are to my current faculty in our Division of Acute Care Surgery (Fig. 8) and my eight surgical critical care fellows for 2009 at the University of Michigan.

Finally, I am most indebted to all of you, the members of this esteemed organization, the Surgical Infection Society, for putting your faith and trust in me. I feel extremely privileged to have been chosen to serve as your President. I look forward to working with you-we have much to do in the year ahead!

\section{Author Disclosure Statement}

No conflicting financial interests exist.

\section{References}

1. Altemeier WA. Sepsis in surgery. Presidential Address, Surgical Infection Society. Arch Surg 1982;117:107-112.

2. Wilson MA. Skin and soft tissue infections: Impact of resistant gram-positive bacteria. Am J Surg 2003;186:35S-41S.

3. Mangram AJ, Horan TC, Pearson ML, et al. Guideline for prevention of surgical site infection, 1999. Hospital Infection Control Practices Advisory Committee. Infect Control Hosp Epidemiol 1999;20:250-278.

4. Klevens RM, Edward JR, et al. Estimating health careassociated infections and deaths in U.S. hospitals, 2002. Public Health Rep 2007;122:160-166.

5. Gaynes RP. Surgical-site infections and the NNIS SSI Risk Index: Room for improvement. Infect Control Hosp Epidemiol 2000;21:184-185.

6. Gaynes RP. Surgical-site infections and the NNIS Basic SSI Risk Index: Room for improvement II. Infect Control Hosp Epidemiol 2001;22:266-267.

7. Gaynes RP, Culver DH, Horan TC, et al. Surgical site infection (SSI) rates in the United States, 1992-1998: The National Nosocomial Infections Surveillance System Basic SSI Risk Index. Clin Infect Dis 2001;33(Suppl 2):S69-S77.

8. National Nosocomial Infections Surveillance (NNIS) System Report, data summary from January 1992-June 2001, issued August 2001. Am J Infect Control 2001;29:404-421.

9. Campbell DA Jr, Henderson WG, Englesbe MJ, et al. Surgical site infection prevention: The importance of operative duration and blood transfusion, results of the first American College of Surgeons National Surgical Quality Improvement Program Best Practices Initiative. J Am Coll Surg 2008; 207:810-820.

10. Malone DL, Genuit T, Tracy JK, et al. Surgical site infections: Reanalysis of risk factors. J Surg Res 2002;103:89-95.

11. Mangram AJ, Horan TC, Pearson ML, et al. Guideline for prevention of surgical site infection, 1999. Hospital Infection Control Practices Advisory Committee. Infect Control Hosp Epidemiol 1999;20:250-278. 
12. Bratzler DW, Houck PM, Richards C, et al. Use of antimicrobial prophylaxis for major surgery: Baseline results from the National Surgical Infection Prevention Project. Arch Surg 2005;140:174-182.

13. Taylor M, Napolitano L. Methicillin-resistant Staphylococcus aureus infections in vascular surgery: Increasing prevalence. Surg Infect 2004;5:180-187.

14. Perl TM. Prevention of Staphylococcus aureus infections among surgical patients: Beyond traditional perioperative prophylaxis. Surgery 2003;134(5 Suppl):S10-S17.

15. Gaynes R, Edwards JR. National Nosocomial Infections Surveillance System: Overview of nosocomial infections caused by gram-negative bacilli. Clin Infect Dis 2005;41: 848-854.

16. Hidron AI, Edwards JR, Patel J, et al. National Healthcare Safety Network Team; Participating National Healthcare Safety Network Facilities. NHSN annual update: Antimicrobial-resistant pathogens associated with healthcareassociated infections: Annual summary of data reported to the National Healthcare Safety Network at the Centers for Disease Control and Prevention, 2006-2007. Infect Control Hosp Epidemiol 2008;29:996-1011.

17. Weigelt JA, Lipsky BA, Tabak YP, et al. Surgical site infections: Causative pathogens and associated outcomes. Am J Infect Control 2010;38:112-120.

18. Morange-Saussier V, Giraudeau B, van der Mee N, et al. Nasal carriage of MRSA in vascular surgery. Ann Vasc Surg 2006;20:767-772.

19. Schelenz S, Tucker D, Georgeu C, et al. Significant reduction of endemic MRSA acquisition and infection in cardiothoracic patients by means of an enhanced targeted infection control programme. J Hosp Infect 2005;60:104-110.

20. Jog $S$, Cunningham R, Cooper $S$, et al. Impact of preoperative screening for MRSA by real-time PCR in patients undergoing cardiac surgery. J Hosp Infect 2008;69:124-130.

21. Trautmann $M$, Stecher J, Hemmer W, et al. Intranasal mupirocin prophylaxis in elective surgery: A review of published studies. Chemotherapy 2008;54:9-16.

22. Van Rijen M, Bonten M, Wenzel R, Kluytmans J. Mupirocin ointment for preventing Staphylococcus aureus infections in nasal carriers. Cochrane Database Syst Rev 2008;8(4): CD006216.

23. Harbath S, Fankhauser C, Schrenzel J, et al. Universal screening for MRSA at hospital admission and nosocomial infection in surgical patients. JAMA 2008;299:1149-1157.

24. Awad SS, Palacio CH, Subramanian A, et al. Implementation of a MRSA prevention bundle results in decreased MRSA surgical site infections. Am J Surg 2009;198:607-610.

25. Popovich KF, Weinstein RA, Hota B. Are communityassociated MRSA strains replacing traditional nosocomial MRSA strains? Clin Infect Dis 2008;46:787-794.

26. Klevens RM, Morrison MA, Nadle J, et al. Active Bacterial Core Surveillance (ABCs) MRSA Investigators. Invasive MRSA infections in the United States. IAMA 2007;298: 1763-1771.

27. Manian FA, Griesnauer S. Community-associated MRSA is replacing traditional healthcare-associated strains in surgical site infections among inpatients. Clin Infect Dis 2008;47:434-435.

28. Kourbatova EV, Halvosa JS, King MD, et al. Emergence of community-associated MRSA USA 300 clone as a cause of healthcare-associated infections among patients with prosthetic joint infections. Am J Infect Control 2005;33: 385-391.
29. Naimi TS, leDell KH, Boxrud DJ, et al. Epidemiology and clonality of community-acquired MRSA in Minnesota; 19961998. Clin Infect Dis 2001;33:990-996.

30. Frazee BW, Lynn J, Charlebois ED, et al. High prevalence of MRSA in emergency department skin and soft tissue infections. Ann Emerg Med 2005;45:311-320.

31. Moran GJ, Krishnadasan A, Gorwitz RJ, et al. EMERGEncy ID Net Study Group. Methicillin-resistant S. aureus infections among patients in the emergency department. $\underline{\mathrm{N} \text { Engl J }}$ Med 2006;355:666-674.

32. King MD, Humphrey BJ, Wang YF, et al. Emergence of community-acquired MRSA USA 300 clone as the predominant cause of skin and soft tissue infections. Ann Intern Med 2006;144:309-317.

33. Edelsberg J, Taneja C, Zervos M, et al. Trends in U.S. hospital admissions for skin and soft tissue infections. Emerg Infect Dis 2009;15:1516-1518.

34. Miller LG, Perdreau-Remington F, Rieg G, et al. Necrotizing fasciitis caused by CA-MRSA in Los Angeles. N Engl J Med 2005;352:1445-1453.

35. Napolitano LM. Severe soft tissue infections. Infect Dis Clin North Am 2009;23:571-591.

36. Ruiz ME, Yohannes $S$, Wladyka CG. Pyomyositis caused by MRSA. N Engl J Med 2005;352:1488-1489.

37. Young LM, Price CS. Community-acquired MRSA emerging as an important cause of necrotizing fasciitis. Surg Infect 2008;9:469-474.

38. Wibbenmeyer LA, Kealey GP, Latenser BA, et al. Emergence of the USA 300 strain of MRSA in a burn-trauma unit. J Burn Care Rehab 2008;29:790-797.

39. May AK, Stafford RE, Bulger EM, et al. Therapeutic Agents Committee of the Surgical Infection Society. Surgical infection guidelines for the treatment of complicated skin and soft tissue infections. Surg Infect 2009;10:469-499.

40. Pepin J, Valiquette L, Alary ME, et al. Clostridium difficileassociated diarrhea in a region of Québec from 1991 to 2003: A changing pattern of disease severity. CMAJ 2004;171: 466-472.

41. Warny M, Pepin J, Fang A, Killgore G, et al. Toxin production by an emerging strain of Clostridium difficile associated with outbreaks of severe disease in North America and Europe. Lancet 2005;366:1079-1084.

42. Labbe AC, Poirier L, MacCannell D, et al. Clostridium difficile infections in a Canadian tertiary care hospital before and during a regional epidemic associated with the BI/NAP1/027 strain. Antimicrob Agents Chemother 2008;52:3180-3187.

43. Zerey M, Paton BL, Lincourt AE, et al. The burden of Clostridium difficile in surgical patients in the United States. Surg Infect 2007;8:557-566.

44. Carignan A, Allard C, Pepin J, et al. Risk of Clostridium difficile infection after perioperative antibacterial prophylaxis before and during an outbreak of infection due to a hypervirulent strain. Clin Infect Dis 2008;46:1848-1843.

45. Sailhamer EA, Carson K, Chang Y, et al. Fulminant Clostridium difficile colitis: Patterns of care and predictors of mortality. Arch Surg 2009;144:433-439.

46. Chan S, Kelly M, Helme S, et al. Outcomes following colectomy for Clostridium difficile colitis. Int J Surg 2008;7:78-81.

47. Byrn JC, Maun DC, Gingold DS, et al. Predictors of mortality after colectomy for fulminant Clostridium difficile colitis. Arch Surg 2008;143:150-154.

48. Navaneethan U, Vege SS, Chari ST, Baron TH. Minimally invasive techniques in pancreatic necrosis. Pancreas 2009;38: 867-875. 
49. Friedland S, Kaltenbach T, Sugimoto M, Soetikno R. Endoscopic necrosectomy of organized pancreatic necrosis: A currently practiced NOTES procedure. J Hepatobiliary Pancreat Surg 2008;16:266-269.

50. Seewald S, Ang TL, Teng KC, Soehendra N. EUS-guided drainage of pancreatic pseudocysts, abscesses and infected necrosis. Dig Endosc 2009;21(Suppl 1):S61-S65.

51. Babu BI, Siriwardena AK. Current status of minimally invasive necrosectomy for post-inflammatory pancreatic necrosis. HPB 2009;11:96-102.

52. Dellinger EP, Tellado J, Soto NE, et al. Early antibiotic treatment for severe acute necrotizing pancreatitis: A randomized, double-blind, placebo-controlled study. Ann Surg 2007;245: 674-683.

53. Nathens AB, Curtis JR, Beale RJ, et al. Management of the critically ill patient with severe acute pancreatitis. Crit Care Med 2004;32:2524-2536.

54. Besselink MG, van Santvoort HC, Buskens E, et al. Dutch Acute Pancreatitis Study Group. Probiotic prophylaxis in predicted severe acute pancreatitis: A randomised, doubleblind, placebo-controlled trial. Lancet 2008;371:651-659.

55. Van Santvoort HC, Bollen TL, Besselink MG, et al. Describing peripancreatic collections in severe acute pancreatitis using morphologic terms: An international interobserver agreement study. Pancreatology 2008;8:593-599.

56. Kollef MH, Napolitano LM, Solomkin JS, et al. Healthcareassociated infection (HAI): A critical appraisal of the emerging threat. Proceedings of the HAI Summit. Clin Infect Dis 2008;47:S55-S99.

57. National Nosocomial Infections Surveillance System. National Nosocomial Infections Surveillance (NNIS) System Report, data summary from January 1992 through June 2004 issued October 2004. Am J Infect Control 2004;32:470-485.

58. Edwards JR, Peterson KD, Andrus ML, et al. NHSN Facilities. National Healthcare Safety Network (NHSN) Report, data summary for 2006, issued June 2007. Am J Infect Control 2007;35:290-301.

59. Edwards JR, Peterson KD, Andrus ML, et al. National Healthcare Safety Network Facilities. National Healthcare Safety Network (NHSN) Report, data summary for 2006 through 2007, issued November 2008. Am J Infect Control 2008;36:609-626. Erratum in: Am J Infect Control 2009; $37: 425$.

60. Wip C, Napolitano L. Bundles to prevent ventilator-associated pneumonia: How valuable are they? Curr Opin Infect Dis 2009;22:159-166.

61. U.S. Centers for Disease Control and Prevention/National Nosocomial Infections Surveillance-January 1992-May 1999. Am J Infect Control 1999;27:520-532.

62. Fridkin S, Weibel SF, Weinstein RA. Magnitude and prevention of nosocomial infections in the intensive care unit. Infect Dis Clin North Am 1997;11:479-496.

63. Rolain JM, Francois P, Hernandez D, et al. Genomic analysis of an emerging multiresistant Staphylococcus aureus strain rapidly spreading in cystic fibrosis patients revealed the presence of an antibiotic inducible bacteriophage. Biol Direct 2009;4:1.

64. Teixeira PJ, Seligman R, Hertz FT, et al. Inadequate treatment of ventilator-associated pneumonia: Risk factors and impact on outcomes. J Hosp Infect 2008;65:361-367.

65. Rea-Neto A, Youssef NC, Tuche F, et al. Diagnosis of ventilator-associated pneumonia: A systematic review of the literature. Crit Care 2008;12:R56.
66. Tejerina E, Esteban A, Fernandez-Segoviano P, et al. Accuracy of clinical definitions of ventilator-associated pneumonia: Comparison with autopsy findings. J Crit Care 2009 Jul 8 [Epub ahead of print].

67. Klompas M. Does this patient have ventilator-associated pneumonia? JAMA 2007;297:1583-1593.

68. Luyt CE, Combes A, Reynaud C, et al. Usefulness of procalcitonin for the diagnosis of ventilator-associated pneumonia. Intensive Care Med 2008;34:1434-1440.

69. Ramirez P, Garcia MA, Ferrer M, et al. Sequential measurements of procalcitonin levels in diagnosing ventilatorassociated pneumonia. Eur Respir J 2008;31:356-362.

70. Linssen CF, Bekers O, Drent M, Jacobs JA. C-reactive protein and procalcitonin concentrations in BAL fluid as a predictor of ventilator-associated pneumonia. Ann Clin Biochem 2008; 45:293-298.

71. Gibot S, Cravoisy A, Levy B, et al. Soluble triggering receptor expressed on myeloid cells and the diagnosis of pneumonia. N Engl J Med 2004;350:451-458.

72. Determann RM, Millo JL, Gibot $S$, et al. Serial changes in soluble triggering receptor expressed on myeloid cells in the lung during development of ventilator-associated pneumonia. Intensive Care Med 2005;31:1495-500.

73. Anand NJ, Zuick S, Klesney-Tait J, Kollef MH. Diagnostic implications of soluble triggering receptor expressed on myeloid cells- 1 in BAL fluid of patients with pulmonary infiltrates in the ICU. Chest 2009;135:641-647.

74. Oudhuis GJ, Beuving J, Bergmans D, et al. Soluble triggering receptor expressed on myeloid cells-1 in bronchoalveolar lavage fluid is not predictive for ventilator-associated pneumonia. Intensive Care Med 2009;35:1265-1270.

75. Cobb JP, Moore EE, Hayden DL, et al. Validation of the riboleukogram to detect ventilator-associated pneumonia after severe injury. Ann Surg 2009 Aug 27. [Epub ahead of print].

76. Napolitano LM, Brunsvold ME, Reddy RC, Hyzy RC. Community-acquired MRSA pneumonia and ARDS: 1-Year followup. Chest 2009;136:1407-1412.

77. Hidron AI, Low CE, Honig EG, Blumberg HM. Emergence of community-acquired MRSA strain USA300 as a cause of necrotizing community-onset pneumonia. Lancet Infect Dis 2009;9:384-392.

78. Kallen AJ, Brunkard J, Moore Z, et al. Staphylococcus aureus community-acquired pneumonia during the 2006-2007 influenza season. Ann Emerg Med 2009;53:358-365.

79. Labandeira-Rey M, Couzon F, Boisset S, et al. Staphylococcus aureus Panton-Valentine leukocidin causes necrotizing pneumonia. Science 2007;315:1130-1133.

80. Wenzel RP, Bearman G, Edmond MB. Community-acquired methicillin-resistant Staphylococcus aureus (MRSA): New issues for infection control. Int J Antimicrob Agents 2007;30: 210-212.

81. Craven DE, Chroneou A, Zias N, Hjalmarson KI. Ventilatorassociated tracheobronchitis: The impact of targeted antibiotic therapy on patient outcomes. Chest 2009;521-528.

82. Nseir S, Favory R, Jozefowica E, et al. VAT Study Group. Antimicrobial treatment for ventilator-associated tracheobronchitis: A randomized, controlled, multicenter study. Crit Care 2008;12:R62-R68.

83. Nseir S, DiPompeo C, Soubrier S, et al. Effect of ventilatorassociated tracheobronchitis on outcome in patients without chronic respiratory failure: A case-control study. Crit Care 2005;9:R238-R245. 
84. Palmer LB, Smaldone GC, Chen JJ, et al. Aerosolized antibiotics and ventilator-associated tracheobronchitis in the intensive care unit. Crit Care Med 2008;36:2008-2013.

85. Berenholtz SM, Pronovost PJ, Lipsett PA, et al. Eliminating catheter-related bloodstream infections in the intensive care unit. Crit Care Med 2004;32:2014-2020.

86. Pronovost P, Needham D, Berenholtz S, et al. An intervention to decrease catheter-related bloodstream infections in the ICU. N Engl J Med 2006;355:2725-2732.

87. Popovich KJ, Weinstein RA, Hota B. Are community-associated MRSA strains replacing traditional nosocomial MRSA strains? Clin Infect Dis 2008;46:787-794.

88. Earley AS, Pryor JP, Kim PK, et al. An acute care surgery model improves outcomes in patients with appendicitis. Ann Surg 2006;244:498-504.

89. von Ridenauer WB, Knipp B, Mallat A, et al. Critical care profile of non-trauma emergency general surgery. Critical Care Med 2007;35(12 Suppl):A70.
90. General Surgery News 2008;May 28:35(5).

91. John Marshall MD. Coming of age. Surg Infect 2008;9:18-20. 92. Solomkin JS, Mazuski JE, Bradley JS, et al. Diagnosis and management of complicated intra-abdominal infection in adults and children: Guidelines by the Surgical Infection Society and the Infectious Diseases Society of America. Surg Infect 2010;11:79-109.

Address correspondence to: Dr. Lena M. Napolitano Division of Acute Care Surgery Department of Surgery University of Michigan $1 C 421$ University Hospital, Box 0033 1500 E. Medical Center Dr. Ann Arbor, MI 48109-0033

E-mail: lenan@umich.edu 
